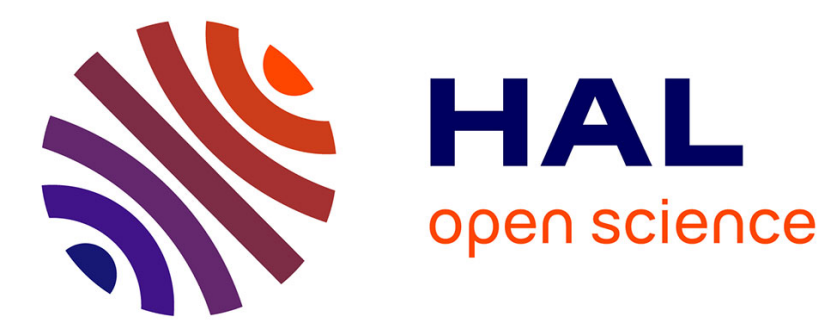

\title{
Method for orthorectification of terrestrial radar maps
}

Marion Jaud, R. Rouveure, P. Faure, L. Moiroux Arvis, M.O. Monod

\section{To cite this version:}

Marion Jaud, R. Rouveure, P. Faure, L. Moiroux Arvis, M.O. Monod. Method for orthorectification of terrestrial radar maps. ISPRS Journal of Photogrammetry and Remote Sensing, 2014, 97, p. 185 p. 194. 10.1016/j.isprsjprs.2014.09.001 . hal-01073024

\section{HAL Id: hal-01073024 https://hal.science/hal-01073024}

Submitted on 8 Oct 2014

HAL is a multi-disciplinary open access archive for the deposit and dissemination of scientific research documents, whether they are published or not. The documents may come from teaching and research institutions in France or abroad, or from public or private research centers.
L'archive ouverte pluridisciplinaire HAL, est destinée au dépôt et à la diffusion de documents scientifiques de niveau recherche, publiés ou non, émanant des établissements d'enseignement et de recherche français ou étrangers, des laboratoires publics ou privés. 


\title{
Method for orthorectification of terrestrial radar maps
}

Marion Jaud*, Raphaël Rouveure*, Patrice Faure, Laure Moiroux-Arvis, Marie-Odile Monod

Affiliation: Irstea, UR TSCF, 24 avenue des Landais - BP 50085, F-63172 Aubière, France.

*Corresponding authors: marion.jaud@irstea.fr (+33 473440711); raphael.rouveure@irstea.fr (+33 473440685)

\begin{abstract}
The vehicle-based PELICAN radar system is used in the context of mobile mapping. The R-SLAM algorithm allows simultaneous retrieval of the vehicle trajectory and of the map of the environment. As the purpose of PELICAN is to provide a means for gathering spatial information, the impact of distortion caused by the topography is not negligible. This article proposes an orthorectification process to correct panoramic radar images and the consequent R-SLAM trajectory and radar map. The a priori knowledge of the area topography is provided by a digital elevation model. By applying the method to the data obtained from a path with large variations in altitude it is shown that the corrected panoramic radar images are contracted by the orthorectification process. The efficiency of the orthorectification process is assessed firstly by comparing R-SLAM trajectories to a GPS trajectory and secondly by comparing the position of Ground Control Points on the radar map with their GPS position. The RMS positioning error moves from $5.56 \mathrm{~m}$ for the raw radar map to $0.75 \mathrm{~m}$ for the orthorectified radar map.
\end{abstract}

\section{Keywords}

FMCW radar; orthorectification; radar cartography; DEM

\section{Introduction}

Usually a map translates a three-dimensional environment into a two-dimensional picture. The aim of geocoding is to reconstruct the correct imaging geometry so that each image pixel is associated with its position on the earth. In general, remote-sensing data are affected by internal distortions due to the sensor or the platform (Richards and Jia, 2006). They are also affected by distortions due to topographic effects. Today the increasingly fine resolution (sub-meter level) requires the impact of distortions to be taken into account, particularly when the aim is to provide a basis for gathering spatial information. Moreover, as mentioned by Liu et al. (2004), the presence of geometric distortions inhibits the alignment and co-registration of topographic data with other geospatial data layers. "Ortho-rectification" is a procedure that removes distortions from the image, creating an "ortho-image" with features positioned as they would be in a planimetric map (Novak, 1992). Without orthorectification, scale is not constant in the image and accurate measurements of distance are impossible. Generally speaking, an ortho-image refers to aerial photographs or satellite images. Nevertheless, the concept of orthorectification can be extended to any $2 \mathrm{D}$ remote sensing data in a $3 \mathrm{D}$ environment. 
Many papers address the questions of distortion and terrain corrections for radar images. Naraghi et al. (1983) presented a method to create geometrically rectified radar imagery by matching SAR data with a digital terrain model. Domik et al. (1984) proposed a method to orthorectify satellite or aerial radar images using topographic height information derived from stereo-radar. More recent studies also relate mainly to satellite or aerial data (Liu et al., 2004; Loew and Mauser, 2007; Zhang et al., 2012).

This study focuses on data provided by PELICAN radar (Rouveure et al., 2008). The PELICAN radar is a terrestrial radar system, which can be mounted on top of a vehicle. This scientific prototype developed by Irstea lab (French National Research Institute of Science and Technology for Environment and Agriculture) is not commercially available. Thanks to its rotating antenna, the system provides maps of the surrounding environment. For each point of the surface, the radartarget distance is measured; this is the slant range distance. The corresponding true horizontal distance (called ground range distance or planimetric distance) must be calculated. In this case, the situation is greatly different from correcting SAR images. Indeed, in the case of a radar system mounted upon a vehicle, since it is approximately situated at ground level, the radar scans the environment in the horizontal plane. Thus the effects caused by the land topography are different from those found on satellite or aerial SAR images. After a brief description of the PELICAN radar system and of the radar map construction process, the article shows how the topography can affect the geometry of radar datasets. A method is proposed to correct these effects in order to "orthorectify" the datasets.

\section{Radar acquisition and type of data}

The PELICAN radar system uses the Frequency Modulated Continuous Wave (FMCW) principle as described in details in (Rouveure et al., 2009) and (Monod, 1995). Waves are emitted through an antenna (aperture angle $20^{\circ}$ vertical, $5^{\circ}$ horizontal) which rotates in a horizontal plane, so that a strip of ground perpendicular to the vehicle displacement plane is illuminated. A portion of the emitted wave is reflected back towards the radar antenna. Following FMCW radar theory, the radar target distance is computed from the beat frequency resulting from the interference between the emitted wave and the reflected wave (Skolnik, 1980). The PELICAN radar carries out a complete scan in one second. An image is built up from the successive angular scans recorded during the antenna rotation. The main technical characteristics of the PELICAN radar are detailed in Table 1. Thanks to its small size $(30 \times 30 \times 30 \mathrm{~cm})$ the PELICAN radar can be easily loaded onto different mobile platforms (Fig. 1).

Table 1. Main characteristics of PELICAN radar

\begin{tabular}{|l|l|}
\hline Transmitted power & $50 \mathrm{~mW}$ \\
Antenna gain & $20 \mathrm{~dB}$ \\
Carrier frequency & $24 \mathrm{GHz}$ \\
Range & $100 \mathrm{~m}$ \\
Angular / Distance resolution & ${ }^{\mathrm{a}}$ \\
Accuracy (on canonical target) $^{\circ} / 1 \mathrm{~m}$ \\
Size / Weight & $2 \mathrm{~cm}$ \\
\hline
\end{tabular}

${ }^{a}$ On a panoramic radar image. 


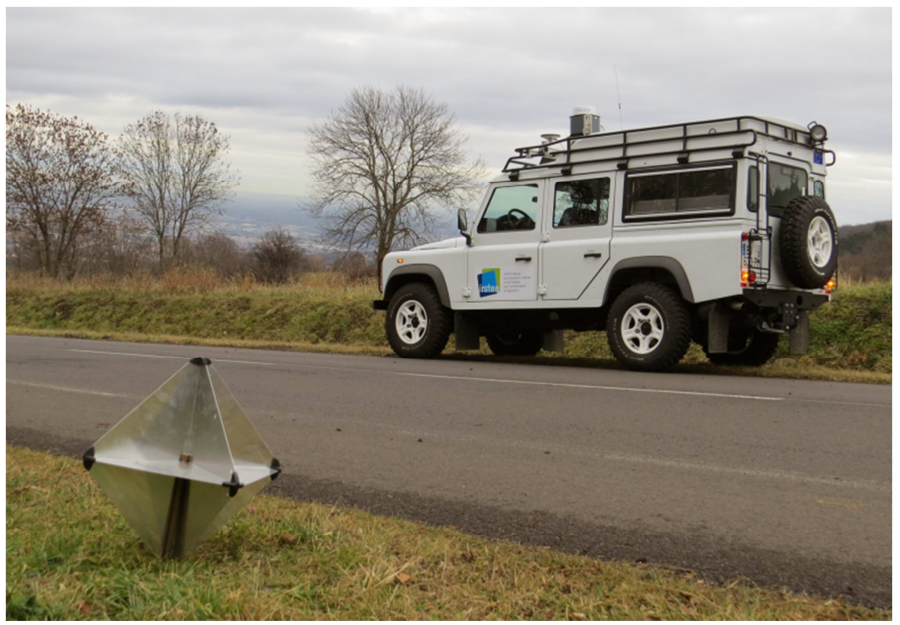

Fig. 1: The PELICAN radar system loaded on an all-terrain vehicle with a trihedral reflector in the foreground.

As for MiSAR system (Saur et al., 2007 ; Magnard et al., 2010), the whole radar map is built gradually, by assembling successive radar images. But, the building process of the PELICAN radar map, described step by step in Fig. 2, is quite different since it is based on Simultaneous Localization And Mapping (SLAM) process (Rouveure et al., 2009).

The first stage is the construction of a "panoramic radar image". A $360^{\circ}$ radar scan in the horizontal plane leads to a polar image (Fig. 2) built up from radar-target distances measured by FFT techniques at each degree of antenna rotation in the horizontal plane. The distance and the angular resolution in the polar image are respectively about $1 \mathrm{~m}$ and $5^{\circ}$. At the end of a complete antenna scan, the intra-scan distortions due to vehicle motion during antenna rotation are corrected and the speckle is filtered. De-speckling is achieved by multi-look filtering, making a spatial integration of several independent images of the scene from slightly different aspects and combining them noncoherently into a single image. Intra-scan distortion corrections and de-speckling are using data from two proprioceptive sensors (odometer and gyrometer) through a dead-reckoning phase, considering a curvilinear trajectory and a constant speed during each antenna rotation. The $1025 \times 1025$ pixel image computed is called "panoramic radar image" (Fig. 3a).

The second stage consists in radar map and trajectory construction through the "R-SLAM" algorithm. The radar map is computed independently of the platform dynamics and of the radar position on the vehicle. For the $\mathrm{n}^{\text {th }}$ panoramic radar image, this approach includes the following steps (Fig. 2):

i) 3D cross-correlation (two translations and one rotation) between the $n^{\text {th }}$ radar scan and the previously constructed map.

ii) The maximum of the correlation matrix gives an estimate of the radar inter-scan displacement and rotation $(\mathrm{dx}, \mathrm{dy}, \mathrm{d} \theta)$.

iii) Map updating merging the $\mathrm{n}^{\text {th }}$ panoramic radar image with the previously recorded map and trajectory updating utilizing successive inter-scan displacements and rotations.

The final radar map is a gray-scale raster, with a spatial grid sampling of $20 \mathrm{~cm}$. The relative radar trajectory computed simultaneously is called "R-SLAM trajectory". This R-SLAM trajectory and the radar map are computed independently of GPS data. 
The 2D map is finally georeferenced either by taking advantage of GPS recording or by manual or automatic matching to an orthophotograph, as described in Jaud et al. (2013).

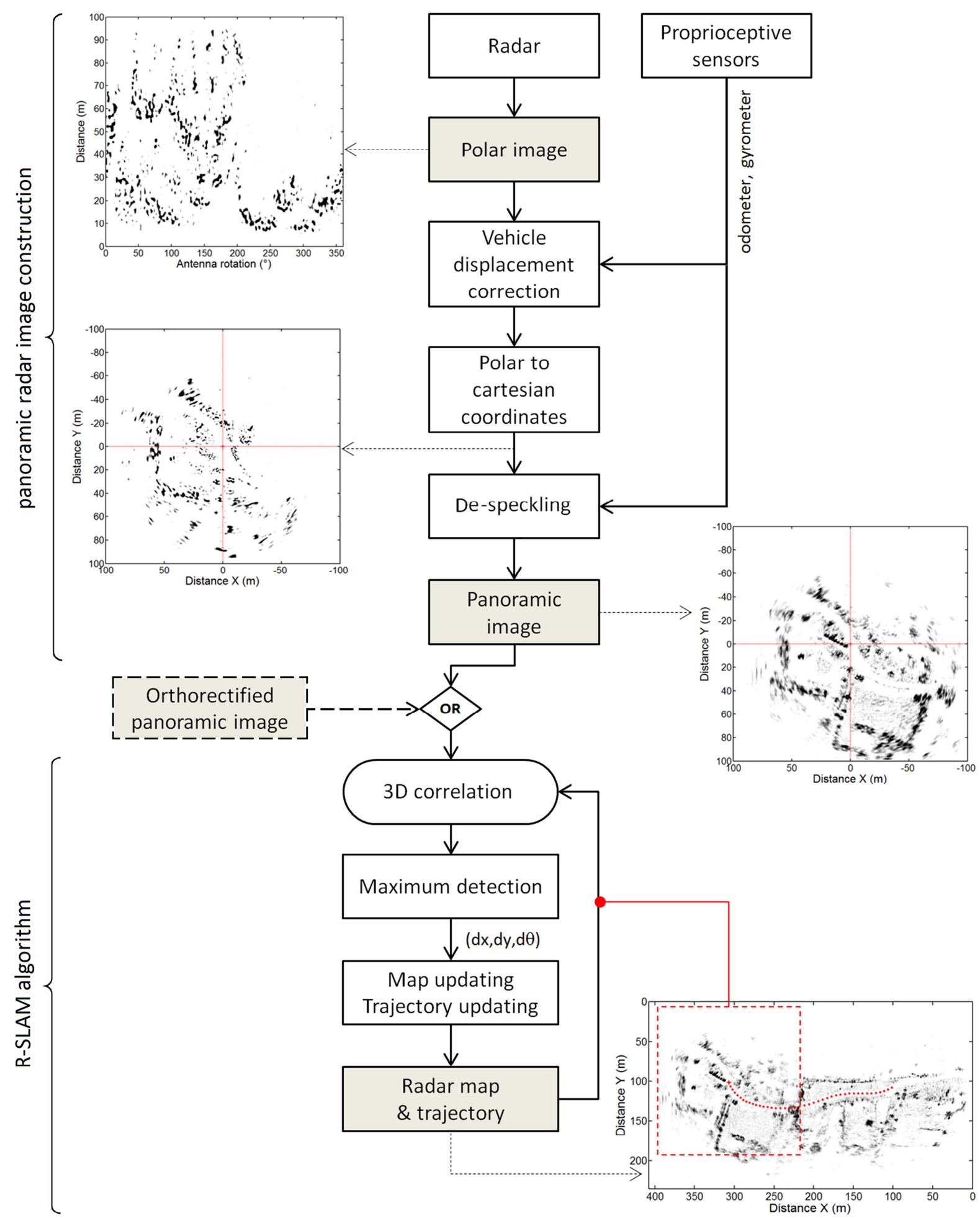

Fig. 2: Main steps of the radar map building process. 

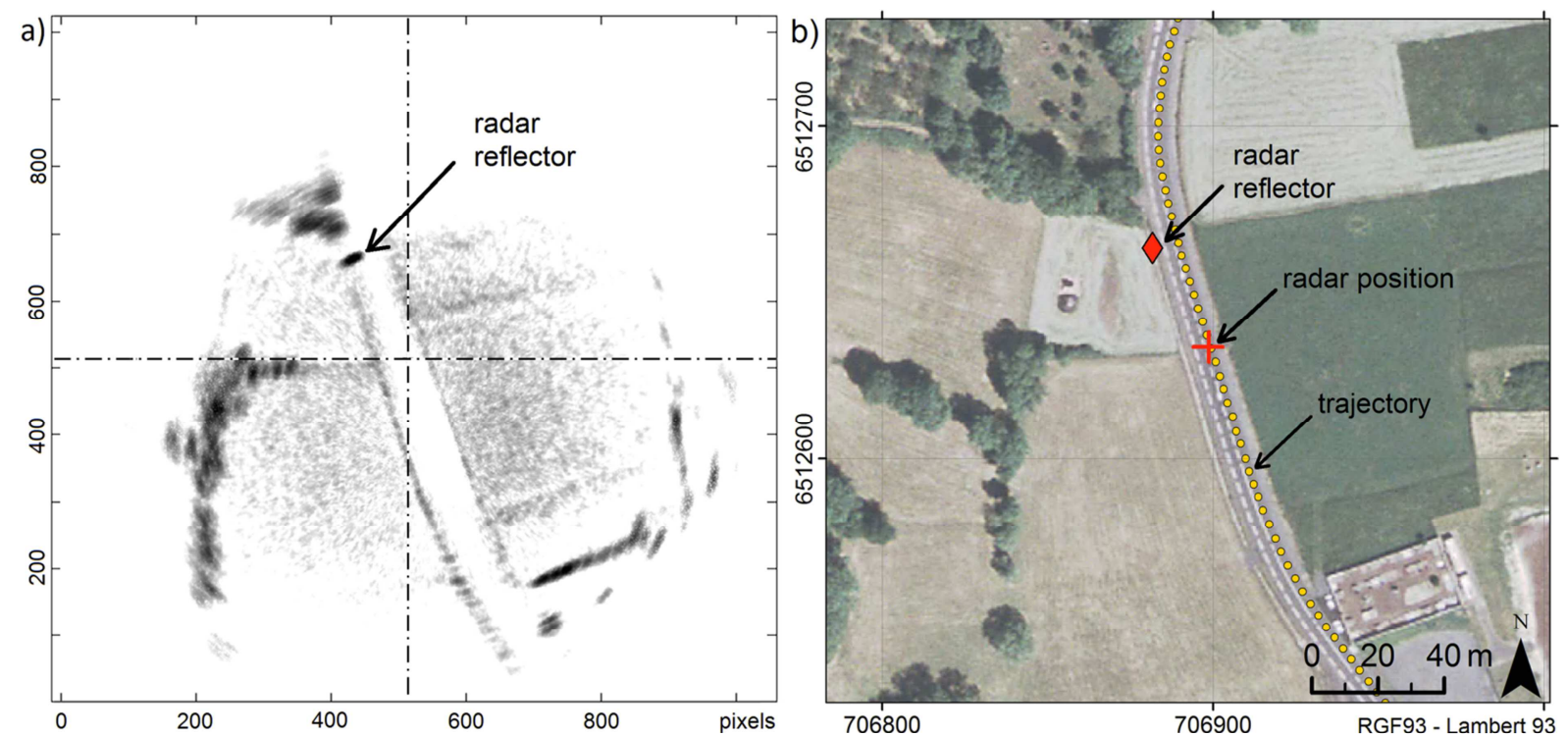

Fig. 3: (a) Example of a "panoramic radar image" centered on the radar position and (b) the corresponding area on the RGB orthophotograph (BD ORTHO ${ }^{\circledR}$ - CIGN - Paris - 2008)).

\section{Effects of the topography on radar data}

Due to the scale of the study (from a few hundred meters to a few kilometers), the curved geometry of Earth's surface is not taken into account. Furthermore, the internal distortions due to the sensor characteristics are not considered.

As mentioned in Meier et al. (1993) and Loew and Mauser (2007), the relief effects can be divided in two main categories: i) radiometric effects, and ii) geometric effects. As reported by Loew and Mauser (2007), rugged terrain changes the recorded brightness values due to changes in the local scattering area and changing scattering mechanisms due to different incident angles. In this paper, we focus on mapping applications without quantitative radiometric analysis. Radiometric terrain effects will not therefore be further detailed.

As for satellite SAR images (Curlander and McDonough, 1991; Meier et al., 1993), precise terrain geocoding requires an a priori knowledge of the surrounding land topography and additional information about the displacement of the vehicle. In the case of PELICAN radar, geometric terrain effects have two main consequences on radar data:

i) change in the radar ground coverage;

ii) distortion of the map due to the difference between slant distance and the planimetric distance or ground range distance.

With regard to ground coverage, the change is particularly appreciable when the acquisition plane remains horizontal while the surrounding environment is sloped. In this configuration, the distance of the intersection of the radar beam with the ground is increased on the downhill side and decreased on the uphill side (Fig. 4a). The incidence angle is also modified. However, when the acquisition plane is parallel to the terrain slope, the ground coverage and the angle of incidence are quasi-similar to an acquisition on a flat area (Fig. 4b). Therefore, according to the path, different terrain configurations can appear at the same time depending on the observation direction. 
a)

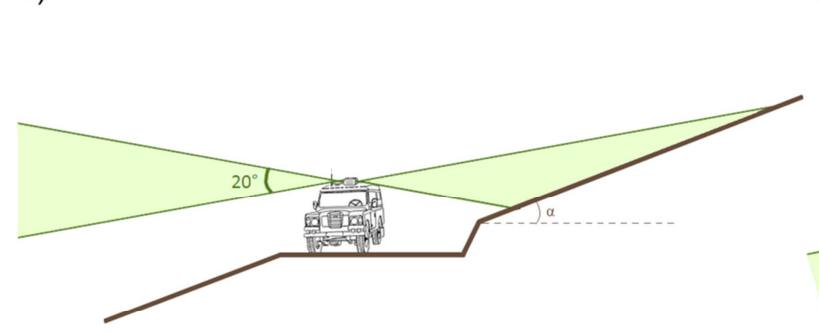

b)

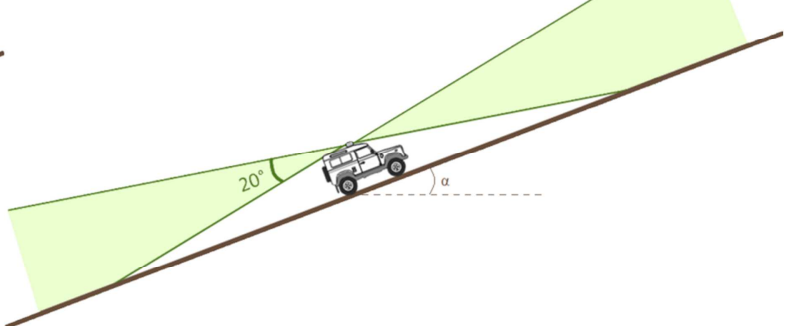

Fig. 4: Illustration of relief effects on the ground coverage of the radar beam.

\section{Orthorectification process}

The required inputs for the orthorectification process are: i) panoramic radar images and their orientation relative to North, and ii) a Digital Elevation Model (DEM) of the area, assumed to be available. Each panoramic radar image is initially acquired as a slant range image, that is to say each target is located relatively to the radar position. It is observed that the topographical variations affect the distance with which targets in a specified direction are displayed on a radar scan. On sloped ground, the slant range image is also affected by geometric distortions. When combining the panoramic images in order to build the radar map, these deviations are compounded and are then very difficult to quantify. Indeed, as the vehicle moves forward, the line of sight of a given feature varies from one panoramic image to another. Therefore, each radar panoramic image must be individually corrected in order to create an "orthorectified panoramic image". The orthorectified panoramic images are then fed back into the R-SLAM algorithm (Fig. 2) so as to build an orthorectified radar map and an orthorectified trajectory.

The land topography leads to an overvaluation of the measured slant range distance $D$ in comparison with the ground range planimetric distance $\rho$ (Fig. 5a).

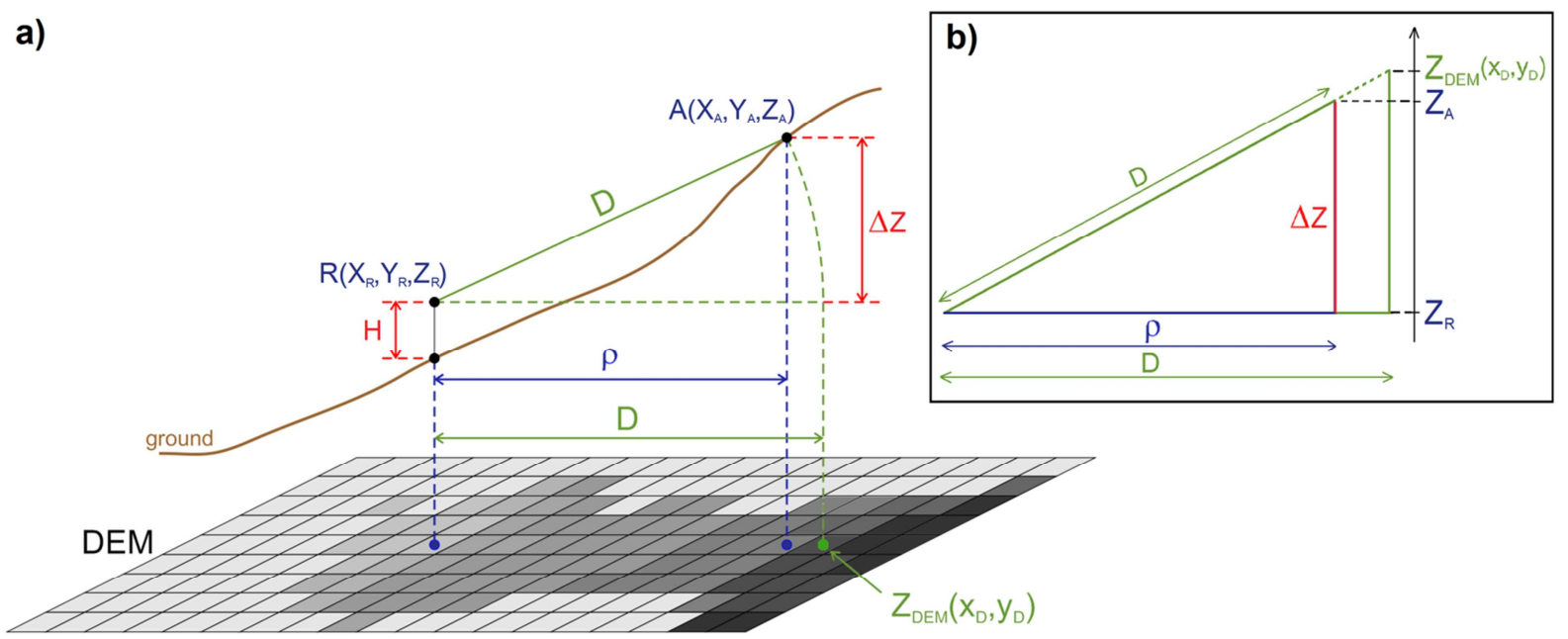

Fig. 5: Definition of the parameters used in the orthorectification process.

From Fig. $5 b$, it can be seen that the planimetric distance $\rho$ is provided by:

$$
\rho=\sqrt{D^{2}-\Delta Z^{2}}
$$


where $D$ refers to the slant range distance separating the radar from a point in the environment. $\Delta Z$ is the elevation difference between the points of the scanned environment and the radar. Orthorectifying the panoramic radar images involves matching each radar echo with the corresponding cell of the DEM. As $D$ is overestimated, $\Delta Z$ cannot be directly retrieved from the DEM. The orthorectification process, summarized in Fig.6, takes place in the following steps:

i) North-orienting the radar panoramic image, initially centered on the radar position. The rotation angle $A z$ of the first panoramic image is deduced from the azimuth of the mobile platform. This heading parameter is computed from the trajectory measured by the GPS receiver. The following panoramic images are oriented using the onboard gyrometer. Knowing the radar position $R\left(X_{R}, Y_{R}, Z_{R}\right)$ measured with a centimetric GPS and the panoramic image resolution, each pixel of the raw panoramic image can then be expressed in the same coordinates system as the DEM.

ii) Finding out the elevation difference $\Delta Z$. The cell $\left(x_{D}, y_{D}\right)$ is the position in the raw panoramic image. The corresponding altitude $Z_{D E M}\left(\mathrm{X}_{D}, \mathrm{Y}_{D}\right)$ is retrieved from the DEM. The elevation $Z_{R}$ of the radar is measured with the GPS.

From Fig. $5 b$, it can be seen that:

$$
\frac{\rho}{D}=\frac{\Delta Z}{Z_{D E M}\left(x_{D}, y_{D}\right)-Z_{R}}
$$

$\Delta Z$ can then be expressed as a function of $\rho$ by:

$$
\Delta Z=\frac{\rho\left[Z_{D E M}\left(x_{D}, y_{D}\right)-Z_{R}\right]}{D}
$$

iii) Computing the planimetric distance $\rho$ combining (1) and (3):

$$
\rho=\frac{D}{\sqrt{1+\left[\left(Z_{D E M}\left(x_{D}, y_{D}\right)-Z_{R}\right) / D\right]^{2}}}
$$

A shift $|D-\rho|$ below the radar map sampling $(20 \mathrm{~cm})$ does not affect the radar map geometry. The minimum elevation difference $\Delta Z$ affecting the radar map geometry at a slant range distance $D$ can be deduced from (1):

$$
\Delta Z \geq \pm 0.2 \sqrt{10 D-1}
$$

The height of the radar relative to the ground, $\mathrm{H}=2.80 \mathrm{~m}$, is taken into account in the orthorectification process. This height $\mathrm{H}$ may increase the ground elevation difference on the downhill side (and respectively reduce the ground elevation difference on the uphill side). Near the sensor the shift due to $\mathrm{H}$ may predominate over purely topographical effects. 


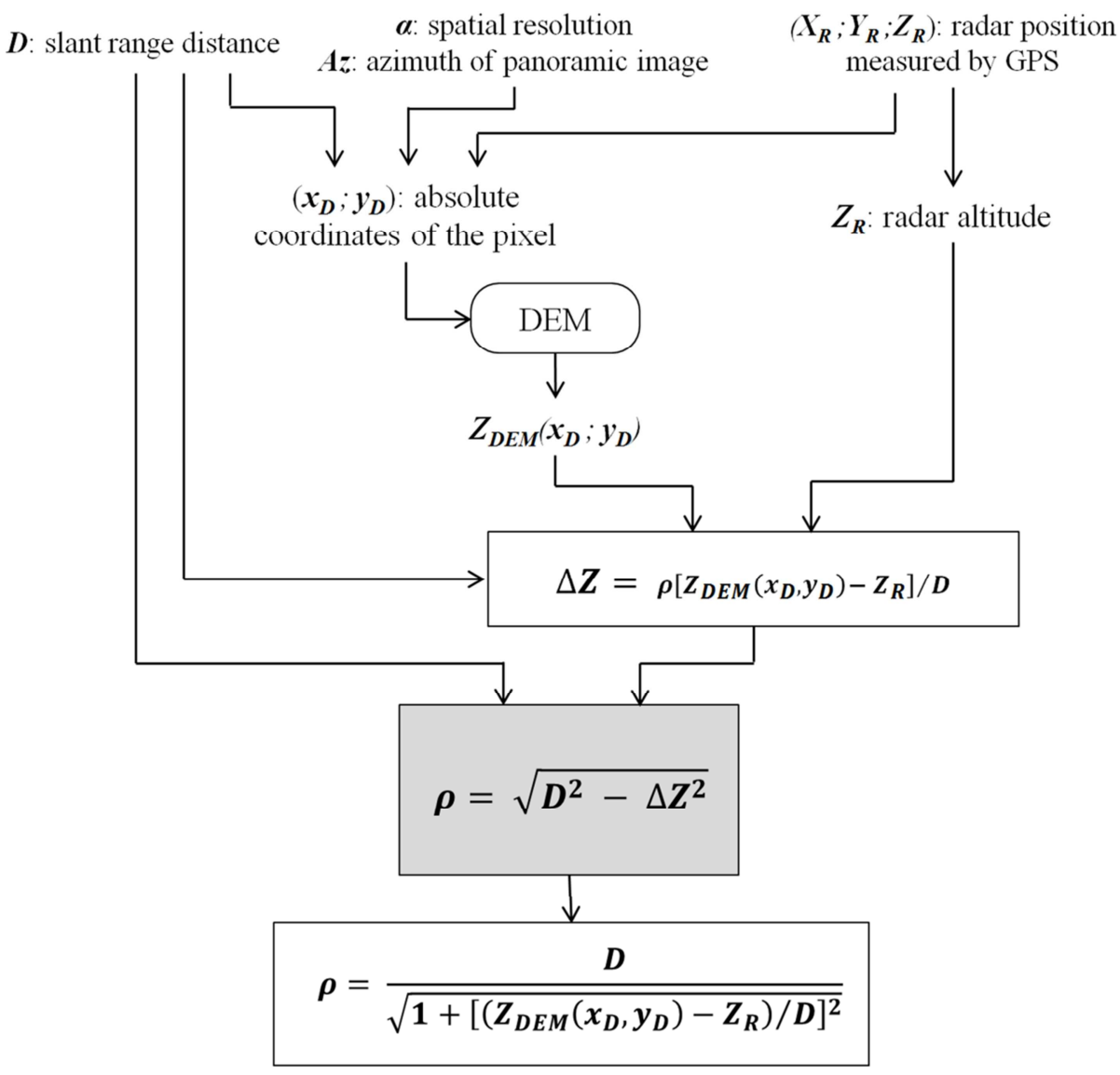

Fig. 6: Main steps of the orthorectification process.

\section{Ground-truth validation}

\section{1-Experimental implementation}

This correcting method was tested on a dataset collected between Opme $(670 \mathrm{~m})$ and Romagnat (510 m) in Auvergne, France (Fig. 7). The path is a $2.5 \mathrm{~km}$ section of a sloping road with a difference in altitude of $160 \mathrm{~m}$. The radar equipment was mounted on the top of an all-terrain vehicle, $2.80 \mathrm{~m}$ above the ground (Fig. 1). During data collection the speed of the vehicle did not exceed $30 \mathrm{~km} / \mathrm{h}$. The PELICAN radar collected 730 panoramic radar images. A GNNS antenna was set up beside the radar and connected to a ProFlex ${ }^{\circledR} 500$ GNSS receiver. As the vehicle is not equipped with an Inertial Measurement Unit (IMU), the effects of the lever arm between the radar and the GNSS antenna (about $50 \mathrm{~cm}$ ) cannot be corrected. The lever arm was therefore neglected. Throughout the acquisition session the radar position was measured at the rate of one position per second. Four reference stations of the French GNSS permanent network (RGP) are situated within a radius of 12 $\mathrm{km}$. After post-processing, the positioning accuracy obtained is $1 \mathrm{~cm}$ in the horizontal plane and $1 \mathrm{~cm}$ in the vertical plane. 


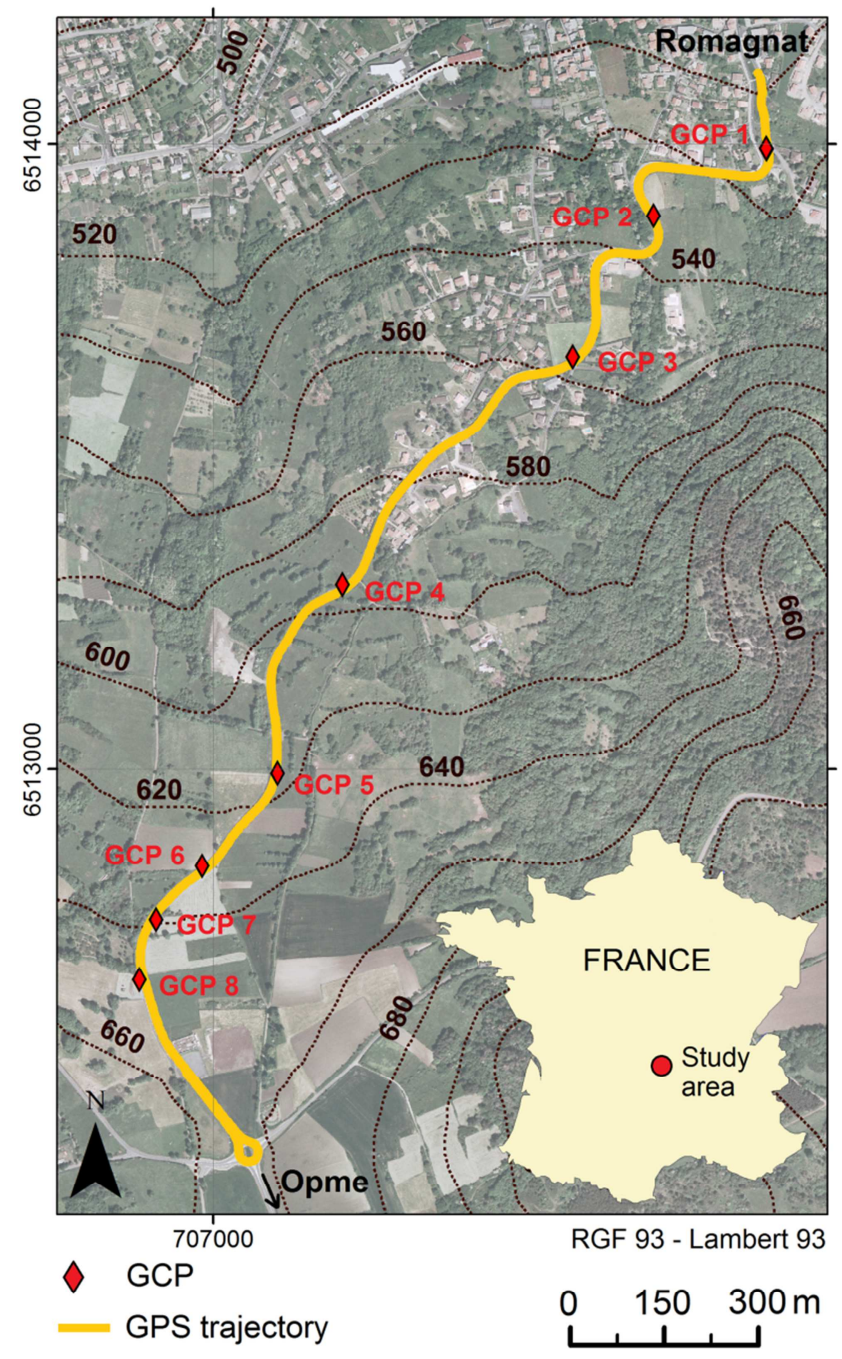

Fig. 7: Study area: a $2.5 \mathrm{~km}$ section of a sloping road, between Opme and Romagnat (Auvergne, France). The total difference in altitude is about $160 \mathrm{~m}$. Eight reflectors (GCP) are distributed along the path.

In order to assess the efficiency of the orthorectification process, Ground Control Points (GCP) have been created. Metallic trihedral radar reflectors (Fig. 1 and Fig. 7) have been erected on the study area. These reflectors have been georeferenced using a ProFlex ${ }^{\circledR} 500$ GNSS receiver and postprocessing. The accuracy on their position is $1 \mathrm{~cm}$. As the highly reflective metallic trihedra appear as black spots on the radar map (Fig. 3a), they can be accurately identified on the radar dataset.

The presented results have been georeferenced in RGF 93 - Lambert 93, the French official coordinate system, based on GRS 80 ellipsoid. The DEM related to the study area is a $1700 \mathrm{~m} \times 2180$ $\mathrm{m}$ extract from the BD Alti ${ }^{\circledR}$, an altimetric database provided by IGN (French National Geographic Institute). On the study area, this database is computed by means of photogrammetric restitution. As the spatial resolution is only $25 \mathrm{~m}$, the BD Alti ${ }^{\circledR}$ extract has been beforehand interpolated on an oversampled grid of $1 \mathrm{~m}$ resolution.

\section{2- Results of the orthorectification process}

Fig. 8 depicts the effects of orthorectification on a panoramic radar image. Fig. $8 \mathrm{c}$ is the differential between the raw panoramic radar image (Fig. 8a) and the orthorectified panoramic radar 
image (Fig. 8b). The blue areas correspond to areas where radar echoes were deleted during the orthorectification process, while the red areas correspond to the areas where these echoes appeared. It can be seen that the orthorectification process tends to contract the panoramic images, whether data collection is performed uphill or downhill. This shift can amount to a displacement of up to several pixels in azimuth direction. The areas of the panoramic radar image which are not affected by orthorectification correspond to areas where the height differences are low and induce negligible distortions.
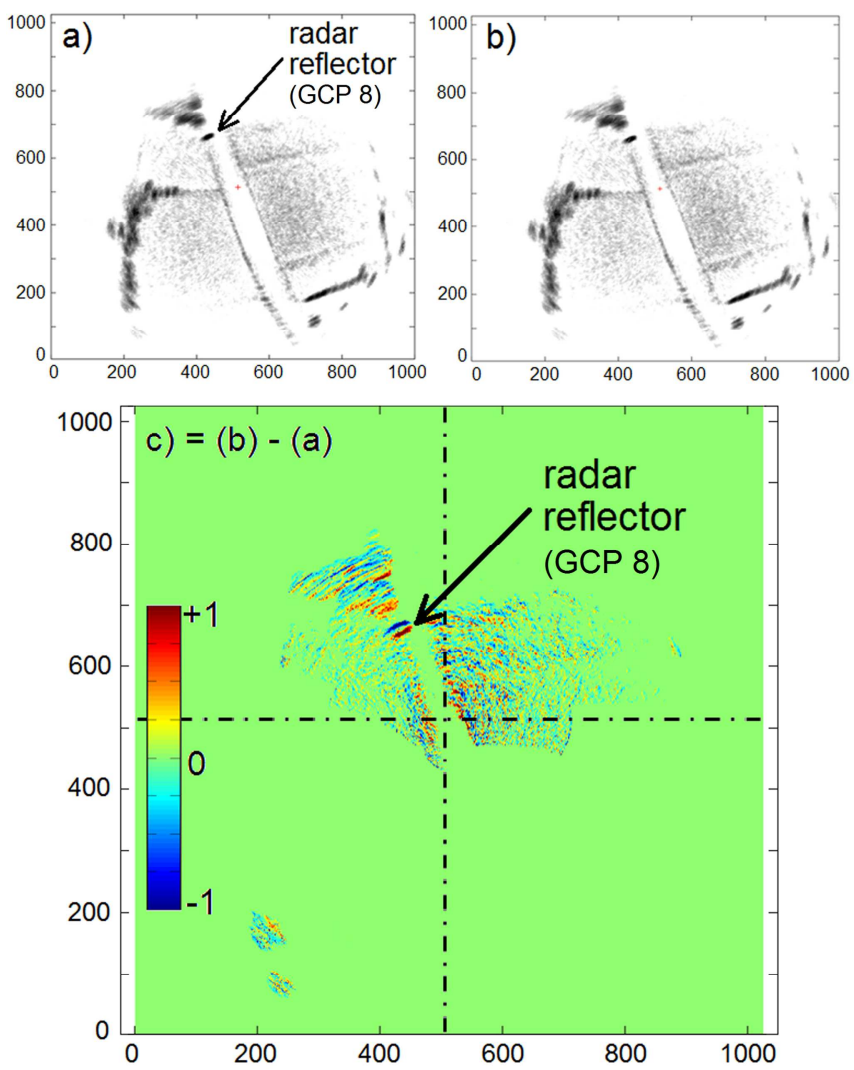

Fig. 8: Comparison of (a) the raw panoramic radar image \#138 and (b) the orthorectified panoramic radar image. (c) The differential between (b) and (a). Blue areas appear where radar echoes have been deleted after the orthorectification process. Red areas are those where these echoes have appeared.

The effects of orthorectification on a panoramic image are quantified by using a georeferenced radar reflector. In the example depicted in Fig. 8, the radar reflector echo is shifted by $0.68 \mathrm{~m}$. To ensure that orthorectification improves the image geocoding, the reflector's positions computed from panoramic images are compared with the position measured by GPS. As each GCP is clearly identifiable on about 40 panoramic images, this comparison can be made for more than 300 images. Table 2 shows the results of this comparison for only one panoramic radar image per GCP. In each case, the positioning RMS error is lower on the orthorectified panoramic radar image. Observing the position of the GCP on raw and orthorectified panoramic images, it can be noticed that the decrease of the error is due to the contraction of the panoramic images by the orthorectification process. Once all the panoramic radar images have been orthorectified, they are associated by the R-SLAM algorithm so as to compute the orthorectified radar map (Fig. 9) and simultaneously the R-SLAM trajectory. 
Author-produced version of the article published in ISPRS Journal of Photogrammetry and Remote Sensing, 2014, 97, 185-194.

The original publication is available at http://www.sciencedirect.com/ doi : 10.1016/j.isprsjprs.2014.09.001

Table 2. Quantification of the orthorectification process effects on the GCP (example given on few panoramic radar images).

\begin{tabular}{|c|c|c|c|c|c|}
\hline $\begin{array}{c}\text { Number } \\
\text { of the } \\
\text { panoramic }\end{array}$ & $\begin{array}{c}\text { Overview of the } \\
\text { panoramic }\end{array}$ & $\begin{array}{c}\text { Number of } \\
\text { the studied } \\
\text { GCP }\end{array}$ & $\begin{array}{l}\text { GPS position of the } \\
\text { radar reflector } \\
\text { (Lambert 93) }\end{array}$ & $\begin{array}{l}\text { Position of the radar } \\
\text { reflector on the raw } \\
\text { panoramic image }\end{array}$ & $\begin{array}{l}\text { Position of the radar } \\
\text { reflector on the ortho- } \\
\text { rectified panoramic } \\
\text { image }\end{array}$ \\
\hline \# 710 & 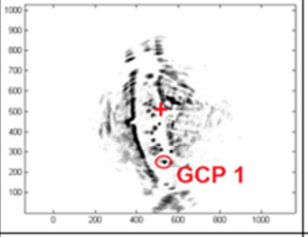 & $\# 1$ & $\begin{array}{l}X: 707883.57 \mathrm{~m} \\
Y: 6513993.02 \mathrm{~m}\end{array}$ & $\begin{array}{l}\mathrm{X}: 707884.08 \mathrm{~m} \\
\mathrm{Y}: 6513992.45 \mathrm{~m} \\
\text { RMS error }=0.77 \mathrm{~m}\end{array}$ & $\begin{array}{l}\mathrm{X}: 707883.88 \mathrm{~m} \\
\mathrm{Y}: 6513993.05 \mathrm{~m} \\
\text { RMS error }=0.31 \mathrm{~m}\end{array}$ \\
\hline \# 629 & 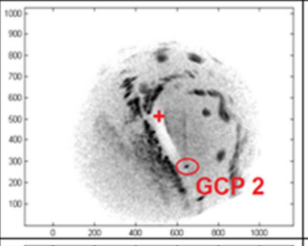 & $\# 2$ & $\begin{array}{l}X: 707703.52 \mathrm{~m} \\
Y: 6513885.94 \mathrm{~m}\end{array}$ & $\begin{array}{l}\mathrm{X}: 707704.59 \mathrm{~m} \\
\mathrm{Y}: 6513885.19 \mathrm{~m} \\
\text { RMS error }=1.30 \mathrm{~m}\end{array}$ & $\begin{array}{l}\mathrm{X}: 707703.99 \mathrm{~m} \\
\mathrm{Y}: 6513885.78 \mathrm{~m} \\
\text { RMS error }=0.49 \mathrm{~m}\end{array}$ \\
\hline \# 502 & sit. & $\# 3$ & $\begin{array}{l}X: 707574.68 \mathrm{~m} \\
Y: 6513659.16 \mathrm{~m}\end{array}$ & $\begin{array}{l}\mathrm{X}: 707575.07 \mathrm{~m} \\
\mathrm{Y}: 6513660.49 \mathrm{~m} \\
\text { RMS error }=1.38 \mathrm{~m}\end{array}$ & $\begin{array}{l}\mathrm{X}: 707574.47 \mathrm{~m} \\
\mathrm{Y}: 6513659.50 \mathrm{~m} \\
\text { RMS error }=0.39 \mathrm{~m}\end{array}$ \\
\hline \# 363 & , & $\# 4$ & $\begin{array}{l}X: 707206.6 \mathrm{~m} \\
Y: 6513295.14 \mathrm{~m}\end{array}$ & $\begin{array}{l}X: 707206.14 \mathrm{~m} \\
Y: 6513294.67 \mathrm{~m} \\
\text { RMS error }=0.65 \mathrm{~m}\end{array}$ & $\begin{array}{l}\mathrm{X}: 707206.54 \mathrm{~m} \\
\mathrm{Y}: 6513294.87 \mathrm{~m} \\
\text { RMS error }=0.28 \mathrm{~m}\end{array}$ \\
\hline \# 268 & (SCP 5 & \# 5 & $\begin{array}{l}X: 707102.95 \mathrm{~m} \\
Y: 6512992.93 \mathrm{~m}\end{array}$ & $\begin{array}{l}\mathrm{X}: 707102.64 \mathrm{~m} \\
\mathrm{Y}: 6512991.80 \mathrm{~m} \\
\text { RMS error }=1.16 \mathrm{~m}\end{array}$ & $\begin{array}{l}\mathrm{X}: 707102.64 \mathrm{~m} \\
\mathrm{Y}: 6512992.60 \mathrm{~m} \\
\text { RMS error }=0.44 \mathrm{~m}\end{array}$ \\
\hline \# 187 & (c) & $\# 6$ & $\begin{array}{l}X: 706982.42 \mathrm{~m} \\
Y: 6512845.63 \mathrm{~m}\end{array}$ & $\begin{array}{l}\mathrm{X}: 706983.36 \mathrm{~m} \\
\mathrm{Y}: 6512846.28 \mathrm{~m} \\
\text { RMS error }=1.14 \mathrm{~m}\end{array}$ & $\begin{array}{l}\mathrm{X}: 706982.56 \mathrm{~m} \\
\mathrm{Y}: 6512845.48 \mathrm{~m} \\
\text { RMS error }=0.20 \mathrm{~m}\end{array}$ \\
\hline \# 187 & , & $\# 7$ & $\begin{array}{l}X: 706908.92 \mathrm{~m} \\
Y: 6512759.92 \mathrm{~m}\end{array}$ & $\begin{array}{l}\mathrm{X}: 706908.36 \mathrm{~m} \\
\mathrm{Y}: 6512758.78 \mathrm{~m} \\
\text { RMS error }=1.26 \mathrm{~m}\end{array}$ & $\begin{array}{l}\mathrm{X}: 706908.96 \mathrm{~m} \\
\mathrm{Y}: 6512759.38 \mathrm{~m} \\
\text { RMS error }=0.54 \mathrm{~m}\end{array}$ \\
\hline \# 138 & $\begin{array}{l}= \\
\bar{z} \\
= \\
=\end{array}$ & \# 8 & $\begin{array}{l}X: 706882.48 \mathrm{~m} \\
Y: 6512662,98 \mathrm{~m}\end{array}$ & $\begin{array}{l}\mathrm{X}: 706882.01 \mathrm{~m} \\
\mathrm{Y}: 6512663,83 \mathrm{~m} \\
\text { RMS error }=0,97 \mathrm{~m}\end{array}$ & $\begin{array}{l}\mathrm{X}: 706882,38 \mathrm{~m} \\
\mathrm{Y}: 6512663,26 \mathrm{~m} \\
\text { RMS error }=0.30 \mathrm{~m}\end{array}$ \\
\hline
\end{tabular}




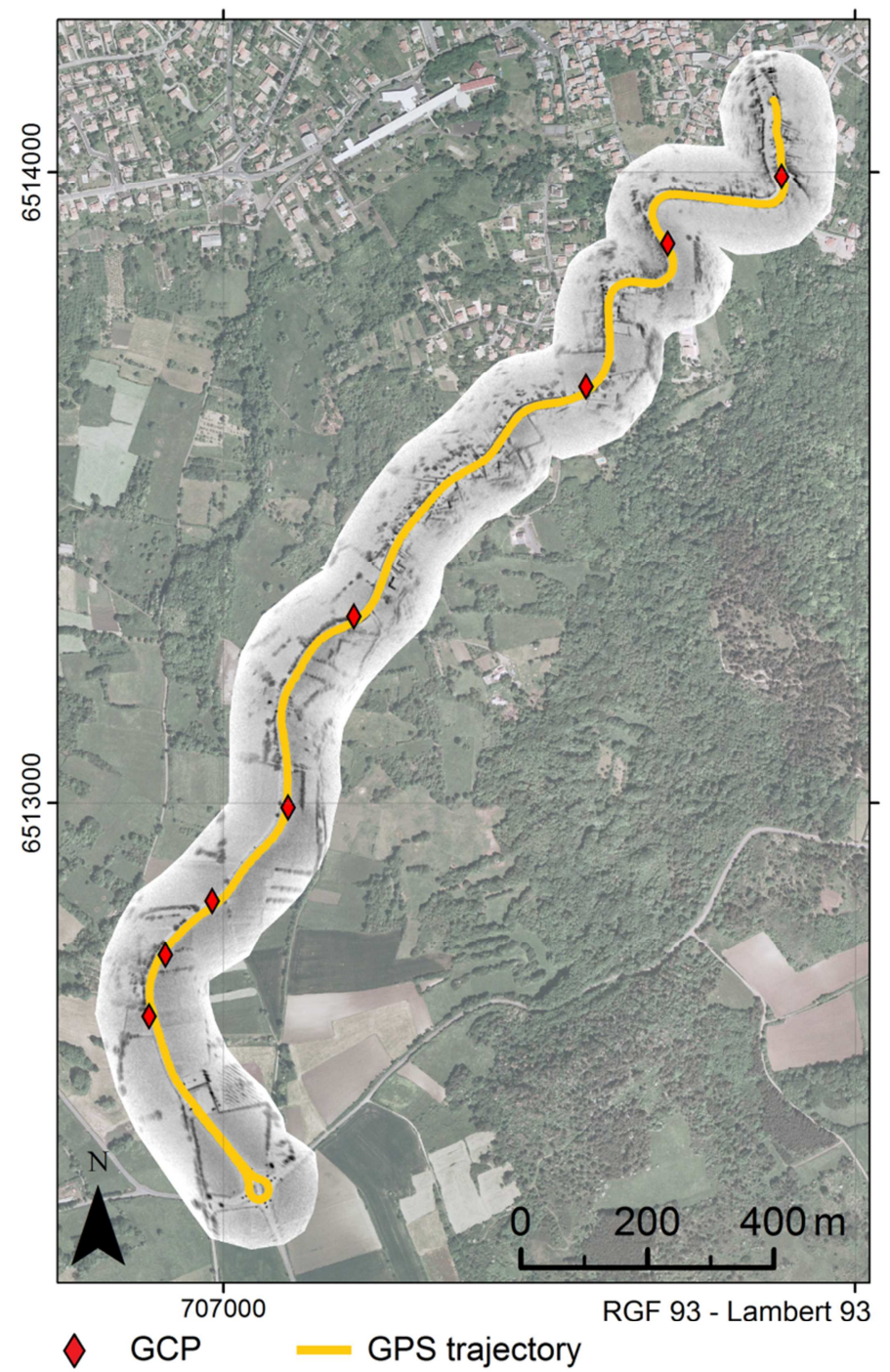

Fig. 9: Orthorectified radar map. Background orthophotograph is extracted from $B D \mathrm{ORTHO}^{\circledR}(\mathrm{CIGN}-$ Paris-2008).

As detailed in section 2, the final radar map is a gray-scale raster with a spatial resolution of 20 $\mathrm{cm}$. As the panoramic radar images have been contracted by slope effects, the radar map and the RSLAM trajectory (see section 2) are also contracted by the orthorectification process. At this point, the "raw R-SLAM trajectory" and the "raw radar map" (computed from non-orthorectified panoramic images) must be distinguished from the "orthorectified R-SLAM trajectory" and the "orthorectified radar map" (computed from orthorectified panoramic images).

At the scale of the radar map, the effects of the orthorectification process can be assessed in two different ways:

i) by comparing respectively the raw and orthorectified R-SLAM trajectories with the GPS trajectory;

ii) by comparing the position of GCP respectively on the raw and on the orthorectified radar map with the GPS position of the GCP.

Fig. 10a is a map of slope (in percentage) of the study area. It should be noted that the survey was performed downhill, from south to north. Fig. 10b depicts on the one hand the difference 
between GPS and raw R-SLAM trajectories (blue curve) and on the other hand the difference between GPS and orthorectified R-SLAM trajectories (red curve). The RMS errors are respectively 6.1 $\mathrm{m}$ and $1.0 \mathrm{~m}$. For the displacement up to $500 \mathrm{~m}$, it can be seen on Fig. 10a that the ground slope is low (approximately $3 \%$ ). As a result the two curves are similar and the error is almost constant. From the distance of $500 \mathrm{~m}$ to $1900 \mathrm{~m}$ the average slope is $6.5 \%$. The difference between GPS and raw RSLAM trajectories (blue curve) increases steadily since errors due to topographical distortions accumulate. From $1900 \mathrm{~m}$ to the end of the path the ground slope is around $11 \%$. The slope of the blue curve rises dramatically because of the distortions due to relief effects. The gap between GPS and raw R-SLAM trajectories is thus correlated to the topographic gradient.

On the other hand, thanks to the orthorectification process, the difference between GPS and orthorectified R-SLAM trajectory (Fig. 10b - red curve) remains almost stable throughout the path. This difference corresponds to the georeferencing error of the orthorectified radar map.
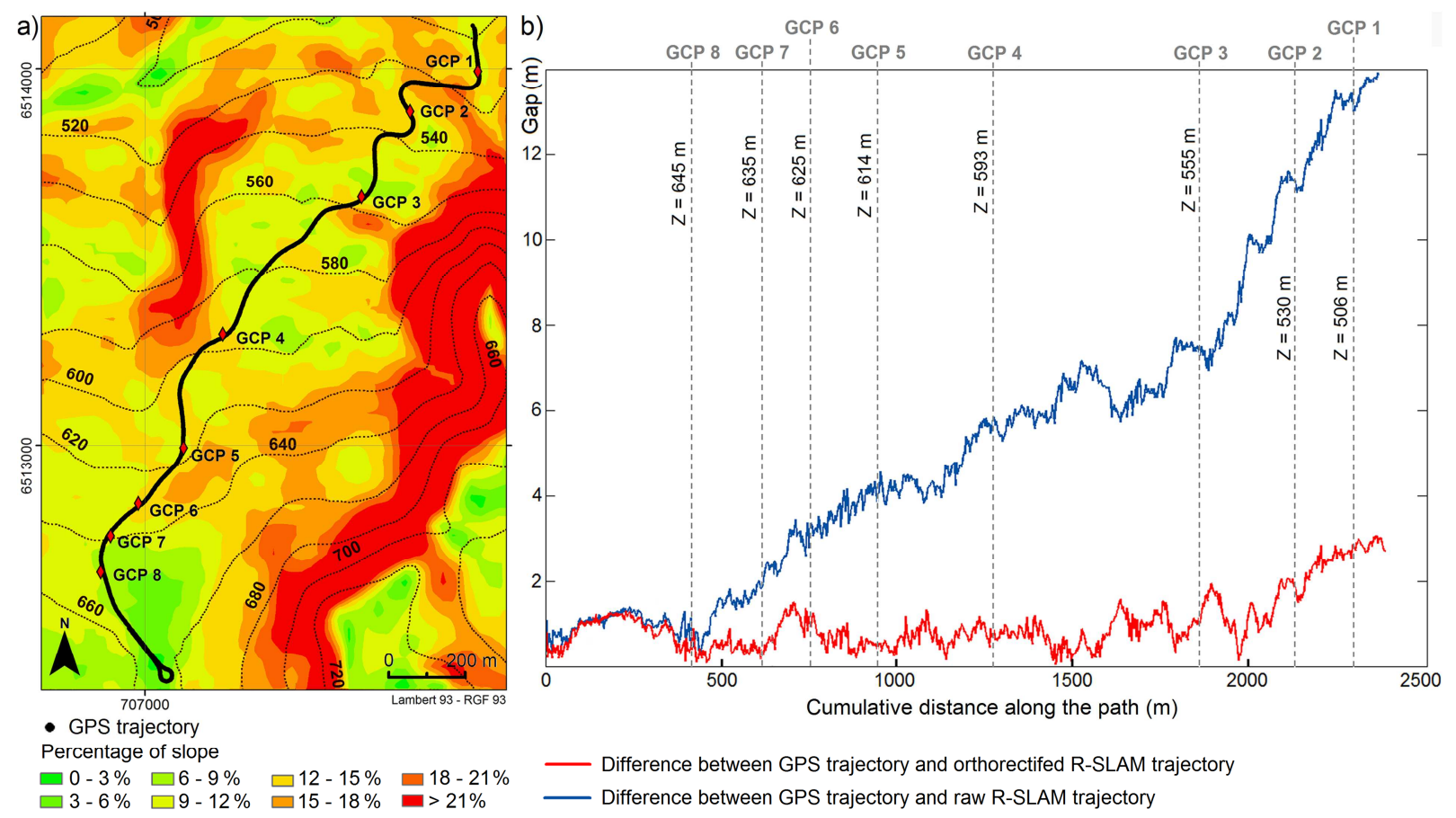

Fig. 10: (a) Map of slope percentage. (b) Difference of the raw R-SLAM trajectory (blue curve), respectively the orthorectified R-SLAM trajectory (red curve) with the GPS trajectory along the path.

Table 3 summarizes the position of the GCP i) measured by GPS, ii) retrieved from georeferenced raw radar map, and iii) computed from orthorectified radar map. For each GCP, the distance between the position on the radar map and the GPS position is computed. On the orthorectified radar map, the gap barely changes. The total RMS error on the eight GCPs is $0.75 \mathrm{~m}$. On the raw radar map, the RMS error is about $5.56 \mathrm{~m}$. The gap with GPS position increases in the northern part of the study area, at the end of the path. This increase is consistent with the results in Fig. 10 and is due to the cumulative topographical distortion effects.

One limitation of this method lies in the fact that a DEM of the area has to be available. Zhang et al. (2012) mention the impact of DEM errors on SAR geolocation. In the case of PELICAN radar data, the accuracy of the orthorectification process is also highly dependant on the quality of the available DEM. Elevation accuracy of the DEM generally decreases in the steeper slopes (Toutin, 2002), leading 
to errors in the orthorectification process. Indeed, a low resolution tends to smooth the relief variations and erases small-scale features. Moreover, if the resolution of the DEM is too low compared to the radar dataset resolution, the panoramic radar image is not linearly corrected, and shifts are computed on small patches. In such a case, the orthorectified panoramic radar images may present artifacts. Furthermore, depending on whether the available DEM represents the Earth's surface including all objects on it (Digital Surface Model: DSM) or the bare ground surface (Digital Terrain Model: DTM), the result of the orthorectification process may be different.

Table 3. Quantification of the orthorectification effects on the radar map

\begin{tabular}{|c|c|c|c|c|c|}
\hline \multirow{2}{*}{$\begin{array}{l}\text { GCP } \\
\text { ID }\end{array}$} & \multirow{2}{*}{$\begin{array}{l}\text { GPS Position } \\
\text { (Lambert } 93 \\
\text { coordinates) }\end{array}$} & \multicolumn{2}{|c|}{$\begin{array}{l}\text { Position on raw radar map } \\
\text { (Lambert } 93 \text { coordinates) }\end{array}$} & \multicolumn{2}{|c|}{$\begin{array}{l}\text { Position on orthorectified radar } \\
\text { map (Lambert } 93 \text { coordinates) }\end{array}$} \\
\hline & & & RMS error & & RMS error \\
\hline 1 & $\begin{array}{l}X: 707883.57 \mathrm{~m} \\
Y: 6513993.02 \mathrm{~m}\end{array}$ & $\begin{array}{l}X: 707883.53 \mathrm{~m} \\
Y: 6514002.41 \mathrm{~m}\end{array}$ & $9.39 \mathrm{~m}$ & $\begin{array}{l}X: 707882.61 \mathrm{~m} \\
Y: 6513993.60 \mathrm{~m}\end{array}$ & $1.12 \mathrm{~m}$ \\
\hline 2 & $\begin{array}{l}X: 707703.52 \mathrm{~m} \\
\mathrm{Y}: 6513885.94 \mathrm{~m}\end{array}$ & $\begin{array}{l}X: 707703.04 \mathrm{~m} \\
\mathrm{Y}: 6513893.91 \mathrm{~m}\end{array}$ & $7.98 \mathrm{~m}$ & $\begin{array}{l}X: 707703.21 \mathrm{~m} \\
\mathrm{Y}: 6513886.50 \mathrm{~m}\end{array}$ & $0.64 \mathrm{~m}$ \\
\hline 3 & $\begin{array}{l}X: 707574.68 \mathrm{~m} \\
Y: 6513659.16 \mathrm{~m}\end{array}$ & $\begin{array}{l}X: 707574.69 \mathrm{~m} \\
Y: 6513666.36 \mathrm{~m}\end{array}$ & $7.20 \mathrm{~m}$ & $\begin{array}{l}X: 707575.15 \mathrm{~m} \\
Y: 6513659.87 \mathrm{~m}\end{array}$ & $0.85 \mathrm{~m}$ \\
\hline 4 & $\begin{array}{l}X: 707206.60 \mathrm{~m} \\
Y: 6513295.14 \mathrm{~m}\end{array}$ & $\begin{array}{l}X: 707205.76 \mathrm{~m} \\
Y: 6513299.50 \mathrm{~m}\end{array}$ & $4.44 \mathrm{~m}$ & $\begin{array}{l}X: 707206.60 \mathrm{~m} \\
Y: 6513295.66 \mathrm{~m}\end{array}$ & $0.52 \mathrm{~m}$ \\
\hline 5 & $\begin{array}{l}X: 707102.95 \mathrm{~m} \\
Y: 6512992.93 \mathrm{~m}\end{array}$ & $\begin{array}{l}X: 707101.68 \mathrm{~m} \\
Y: 6512996.90 \mathrm{~m}\end{array}$ & $4.17 \mathrm{~m}$ & $\begin{array}{l}X: 707101.96 \mathrm{~m} \\
Y: 6512993.37 \mathrm{~m}\end{array}$ & $1.08 \mathrm{~m}$ \\
\hline 6 & $\begin{array}{l}X: 706982.42 \mathrm{~m} \\
Y: 6512845.63 \mathrm{~m}\end{array}$ & $\begin{array}{l}X: 706981.98 \mathrm{~m} \\
Y: 6512847.58 \mathrm{~m}\end{array}$ & $2.00 \mathrm{~m}$ & $\begin{array}{l}X: 706982.35 \mathrm{~m} \\
Y: 6512846.23 \mathrm{~m}\end{array}$ & $0.60 \mathrm{~m}$ \\
\hline 7 & $\begin{array}{l}X: 706908.92 \mathrm{~m} \\
Y: 6512759.92 \mathrm{~m}\end{array}$ & $\begin{array}{l}X: 706908.77 \mathrm{~m} \\
Y: 6512761.36 \mathrm{~m}\end{array}$ & $1.45 \mathrm{~m}$ & $\begin{array}{l}\text { X: } 706909.30 \mathrm{~m} \\
Y: 6512759.96 \mathrm{~m}\end{array}$ & $0.38 \mathrm{~m}$ \\
\hline 8 & $\begin{array}{l}X: 706882.48 \mathrm{~m} \\
Y: 6512662.98 \mathrm{~m}\end{array}$ & $\begin{array}{l}X: 706882.03 \mathrm{~m} \\
Y: 6512663.67 \mathrm{~m}\end{array}$ & $0.82 \mathrm{~m}$ & $\begin{array}{l}X: 706882.54 \mathrm{~m} \\
Y: 6512663.33 \mathrm{~m}\end{array}$ & $0.36 \mathrm{~m}$ \\
\hline
\end{tabular}

\section{Conclusion}

When using terrestrial radar, topographical variations induce a difference between the measured slant range distance and the planimetric distance. This results in a distortion of panoramic radar images. On the radar map, as the road is sloping, the errors accumulate along the path, the difference between GPS and raw R-SLAM trajectories being correlated to the topographic gradient. In cartographic applications, these topographical effects must be corrected.

To compute planimetric distances, an orthorectification process is proposed. It retrieves from a DEM the difference of altitude between the radar position and every point of the environment scanned during the rotation of the antenna. Panoramic radar images are thus orthorectified. An orthorectified radar map and an orthorectified R-SLAM trajectory can be computed. This orthorectification process improves the georeferencing accuracy of the radar map and the accuracy of the R-SLAM trajectory. Comparing the raw R-SLAM trajectory, respectively the orthorectified trajectory, to the GPS trajectory, the RMS error is $6.1 \mathrm{~m}$, respectively $1.0 \mathrm{~m}$. The gap between GPS and raw R-SLAM 
trajectories appears to be correlated to the topographic gradient. Comparing the position of GCPs on the radar map with their GPS position, it appears that the RMS positioning error moves from $5.56 \mathrm{~m}$ for the raw radar map to $0.75 \mathrm{~m}$ for the orthorectified radar map.

This orthorectification process has to be applied only when the topographic variations are significant enough to affect the quality of panoramic radar images. In addition to these geometric corrections, radiometric corrections of radar datasets should be considered. Finally, the impact of DEM quality could be quantified, by comparing the results of the orthorectification process with a DEM from a national or regional database and with a DEM of the study area computed specifically by mobile laser scanning.

\section{Acknowledgements}

This work is part of PELICAN Project No. ANR-2010-EMMA-033 supported by the Agence Nationale de la Recherche. The Project was labelled by ViaMeca French pole of competitiveness.

\section{References}

Curlander, J.C., McDonough, R., 1991. Synthetic aperture radar: Systems and signal processing. Wiley Series in Remote Sensing and Image Processing - vol. 5, Wiley, New York.

Domik, G., Raggam, J., Leberl, F., 1984. Rectification of radar images using stereo-derived height models and simulations. International Archives of Photogrammetry, Remote Sensing and Spatial Information Sciences 25 (Part A3), 109-116.

Jaud, M., Rouveure, R., Faure, P., Monod, M.O., 2013. Methods for FMCW radar map georeferencing. ISPRS Journal of Photogrammetry and Remote Sensing 84, 33-42. doi: 10.1016/j.isprsjprs.2013.07.002

Liu, H., Zhao, Z., Jezek, K.C., 2004. Correction of positional errors and geometric distortions in topographic maps and DEMs using rigorous SAR simulation technique. Photogrammetric engineering and remote sensing 70 (9), 1031-1042.

Loew, A., Mauser, W., 2007. Generation of geometrically and radiometrically terrain corrected SAR image products. Remote Sensing of Environment 106 (3), 337-349. doi: 10.1016/j.rse.2006.09.002

Magnard, C., Frioud, M., Meier, E., 2010. Processing, geocoding and mosaicking of MiSAR data. Proc. Dreiländertagung DGPF - OVG - SGPF, Vienna, Austria, 1-3 July, pp. 524-531.

Meier, E., Frei, U., Nüesch, D., 1993. Precise terrain corrected geocoded images. In: G. Schreier (Ed.), SAR Geocoding - Data and Systems, Karlsruhe, pp. 173-185.

Monod, M.O., 1995. Frequency modulated radar: a new sensor for natural environment and mobile robotics. Ph.D. Thesis, Paris VI University, France.

Naraghi, M., Stromberg, W., Daily, M., 1983. Geometric Rectification of Radar imagery using Digital Elevation Model. Photogrammetric engineering and Remote Sensing 49 (2), 195-199. 
Author-produced version of the article published in ISPRS Journal of Photogrammetry and Remote Sensing, 2014, 97, $185-194$. doi : 10.1016/j.isprsjprs.2014.09.001

Novak, K., 1992. Rectification of digital imagery. Photogrammetric engineering and remote sensing 58 (3), 339-344.

Richards, J.A., Jia, X., 2006. Remote Sensing Digital Image Analysis, fourth ed. Springer, Berlin.

Rouveure, R., Monod, M.O., Faure, P., 2008. Mapping of the environment with a high resolution ground-based radar imager. Proc. 14th IEEE Mediterranean Electrotechnical Conference MELECON 2008, Ajaccio, France, 5-7 May, pp. 801-807.

Rouveure, R., Faure, P., Monod, M.O., 2009. Radar Imager for Perception and Mapping in Outdoor Environments. Proc. $11^{\text {th }}$ International Conference of Advanced Concepts for Intelligent Vision Systems ACIVS 2009, Bordeaux, France, 28 September - 2 October, pp. 618-628.

Saur, G., Heinze, N., Krüger, W., Edrich, M., 2007. Video-like MiSAR image sequence processing. Proc. Dreiländertagung DGPF - OVG - SGPF, Basel, Switzerland, 17-21 June, pp. 111-118.

Skolnik, M.I., 1980. Introduction to radar systems. Electrical Engineering Series, McGraw-Hill International Editions, New-York.

Toutin, T., 2002. Impact of terrain slope and aspect on radargrammetric DEM accuracy. ISPRS Journal of Photogrammetry and Remote Sensing 57 (3), 228-240. doi: 10.1016/j.isprsjprs.2012.02.004

Zhang, L., Balz, T., Liao, M., 2012. Satellite SAR geocoding with refined RPC model. ISPRS Journal of Photogrammetry and Remote Sensing 69, 37-49. doi: 10.1016/j.isprsjprs.2012.02.004 